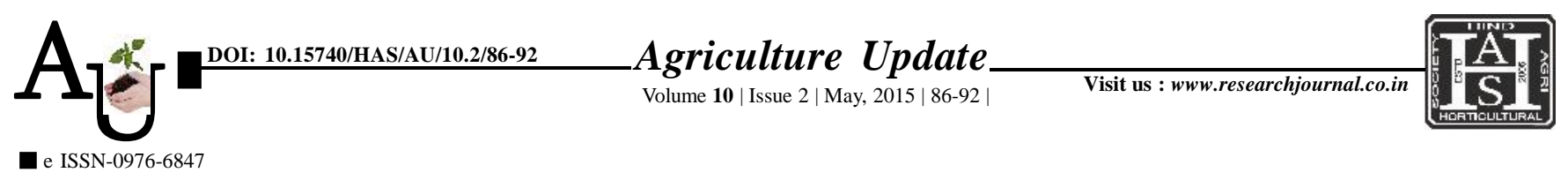

\title{
Research Article: Assessing adoption dynamics vis-a-vis constraints faced apropos water management technologies by trained farmers in Assam
}

\author{
N. DOLEY, S. BARMAN* AND R.K. THAKURIA
}

Article Chronicle: Received : 09.02.2015;

Revised : 01.03.2015; Accepted : 15.03.2015

\section{KEY WoRDs:}

Trained farmers, Adoption, Constraints, SWPA
SUMMARY : The study was conducted in two districts of Assam viz., Jorhat and Golaghat in order to assess the extent of adoption and constraints faced by the farmers in adoption of water management technologies. A purposive cum proportionate random sampling design was followed to select the respondents. All total 70 farmers trained under Scaling up of Water Productivity in Agriculture (SWPA) training programme were selected as respondents from the two districts. The study revealed that the majority of the farmers were under young age category (Below 35 years) with education up to High school level. The average land holding and annual income of the farmers were $1.50 \mathrm{ha}$ and Rs. 44,000, respectively. The extent of social participation of majority of the respondents was low and more than 40 per cent farmers had regular extension contact. The extent of adoption of water management technologies were medium level for majority farmers. Size of operational holding, extent of social participation, extension contact, annual farm income were found to have a strong positive significant relationship with extent of adoption. Major problems faced by the respondents were lack of proper irrigation facilities, lack of follow-up measures, lack of proper practical demonstration, low income level, high cost of irrigation and difficulty in application of irrigation due to land fragmentation, high cost of inputs and unavailability of seeds and fertilizers in time. Proper intervention should be implemented to solve these problems in order to step up the exploitation of the full potential of these water management technologies.

How to cite this article : Doley, N., Barman, S. and Thakuria, R.K. (2015). Assessing adoption dynamics vis$a$-vis constraints faced apropos water management technologies by trained farmers in Assam. Agric. Update, 10(2): 86-92.

Author for correspondence :

\section{S. BARMAN}

Department of

Extension Education,

Assam Agricultural

University, JORHAT

(ASSAM) INDIA

Email: sbarman72@

gmail.com

See end of the article for

authors' affiliations 